\title{
Oncolytic adenovirus: A tool for reversing the tumor microenvironment and promoting cancer treatment (Review)
}

\author{
XIAOXI WANG, LIPING ZHONG and YONGXIANG ZHAO \\ National Center for International Research of Biological Targeting Diagnosis and Therapy, Guangxi Key Laboratory of \\ Biological Targeting Diagnosis and Therapy Research, Collaborative Innovation Center for Targeting Tumor Diagnosis and \\ Therapy, Guangxi Medical University, Nanning, Guangxi Zhuang Autonomous Region 530021, P.R. China
}

Received November 13, 2020; Accepted February 11, 2021

DOI: $10.3892 / o r .2021 .8000$

\begin{abstract}
Immunogene therapy can enhance the antitumor immune effect by introducing genes encoding co-stimulation molecules, cytokines, chemokines and tumor-associated antigens into treatment cells or human cells through genetic engineering techniques. Oncolytic viruses can specifically target tumor cells and replicate indefinitely until they kill tumor cells. If combined with immunogene therapy, oncolytic viruses can play a more powerful antitumor role. The high pressure, hypoxia and acidity in the tumor microenvironment (TME) provide suitable conditions for tumor cells to survive. To maximize the potency of oncolytic viruses, various methods are being developed to promote the reversal of the TME, thereby maximizing transmission of replication and immunogenicity. The aim of the present review was to discuss the basic mechanisms underlying the effects of oncolytic adenoviruses on the TME, and suggest how to combine the modification of the adenovirus with the TME to further combat malignant tumors.
\end{abstract}

\section{Contents}

1. Introduction

2. Oncolytic adenovirus

3. TME of solid tumors

4. Adenovirus modification combined with immune cells in the TME

Correspondence to: Professor Yongxiang Zhao or Professor Liping Zhong, National Center for International Research of Biological Targeting Diagnosis and Therapy, Guangxi Key Laboratory of Biological Targeting Diagnosis and Therapy Research, Collaborative Innovation Center for Targeting Tumor Diagnosis and Therapy, Guangxi Medical University, Nanning, Guangxi Zhuang Autonomous Region 530021, P.R. China

E-mail: yongxiang_zhao@126.com

E-mail: 715065769@qq.com

Key words: oncolytic adenovirus, tumor microenvironment, gene therapy, immune checkpoints
5. Adenovirus modification combined with stromal cells in the TME

6. Adenovirus modification combined with immune checkpoints in the TME

7. Outlooks

\section{Introduction}

Solid tumors are a major cause of mortality in humans (1). Due to the advanced proliferative, invasive and migratory abilities of tumor cells, the prognosis for patients with cancer is extremely poor (2). Effective tumor therapy is disrupted immunosuppression of immune cells in the tumor microenvironment (TME) and tumor specificity of stromal cells (3). For example, chemotherapy, while killing tumor cells, stimulates other cells in the TME to release signals that promote tumor growth, ultimately resulting in treatment tolerance (4). Drug development with specific targeting of tumor cells and the TME will be a promising approach to tumor therapy. Thus, several studies have focused on the transformation of oncolytic adenoviruses $(5,6)$, which can specifically target tumor cells and retain the efficacy of the drug at the tumor site. Gene therapy is a novel approach to cancer treatment (7), which aimed to target any aspect of tumor occurrence (8). Thus, in terms of genetic modification, several strategies have been adopted to overcome obstacles and reverse the TME.

\section{Oncolytic adenovirus}

An adenovirus is a non-enveloped double-stranded DNA virus with a symmetrical icosahedral structure (9). The genome is $\sim 36 \mathrm{~kb}$ in length and can encode $>40$ gene products (10). These gene products are divided into three subtypes based on their transcription start time, including early, middle and late stages (11). Early gene products are predominantly responsible for coding gene regulation, including the E region, while late gene products are predominantly responsible for coding structural proteins, including the $\mathrm{L}$ region $(12,13)$. Among adenovirus subtypes, adenovirus serotype 3 (Ad.3) and adenovirus serotype 5 (Ad.5) are the most commonly studied subtypes, and Ad.5 is the most commonly used subtype (14). Following infection, the oncolytic adenovirus initially recognizes specific receptors on the 
surface of tumor cells and triggers their internalization (15). Subsequently, it enters tumor cells, viral genomes migrate to the nucleus through microtubules, and early viral proteins in the E1 region immediately begin to be transcribed (16). The protein binds to $\mathrm{Rb}$ to release the transcription factor, $\mathrm{E} 2 \mathrm{~F}$, which also activates the cell cycle, allowing oncolytic adenovirus-infected cells to enter the $S$ phase $(6,17)$. Concurrently, the E1A protein maintains p53 stability and inhibits tumor growth by relying on the p53 pathway (18). The release of E2F also triggers the coordinated activation of viral genes, which results in the production of new virions, the lysis of infected cells and the spread of viral offspring (19). The oncolytic adenovirus continuously replicates in tumor cells, eventually lysing tumor cells and infecting other tumor cells via the same mechanism of action (20-23). Due to the large loading capacity of the oncolytic adenovirus vector, therapeutic genes are commonly inserted into the adenovirus vector $(24,25)$. Due to the continuous replication and accumulation of adenoviruses in tumor cells, therapeutic genes are expressed and thus spread, playing a synergistic antitumor role (26).

\section{TME of solid tumors}

The TME is the internal environment for the growth of tumors, which includes tumor cells $(27,28)$, stromal cells (tumor-associated vascular endothelial cells and tumor-associated fibroblasts), immune cells [T lymphocytes and B lymphocytes, tumor-associated macrophages (TAMs), dendritic cells (DCs) and natural killer (NK) cells], the extracellular matrix (ECM) and signaling molecules such as IL-4 and IL-10 (29-31). The ECM includes various proteins, glycoproteins, proteoglycans and other biochemical substances, which regulate vascular endothelial cells and fibroblasts, and promote tumor growth and cell migration (32) (Fig. 1). In the TME, tumor blood vessels are constantly supplying oxygen and nutrients to support tumor growth (28,32-34). When the tumor is exposed to hypoxic conditions locally, tumor blood vessels receive signal stimulation and generate branches from existing blood vessels $(35,36)$. However, the structure of these tumor vessels differs from that of normal vessels, with absence of basement membranes, uneven diameter and size of the tubes, and short circuit of arteries and veins, resulting in tumor interstitial hypertension $(37,38)$. Under hypoxic conditions, tumor cells undergo glycolysis and produce more lactic acid, which lowers the $\mathrm{pH}$ of the TME (39). Proton transport channels exist in all parts of tumor tissues, which transfer the metabolized $\mathrm{H}^{+}$ out of tumor tissues and maintain the $\mathrm{pH}$ in the TME (40-42). However, $\mathrm{pH}$ reduction in normal tissues results in necrosis, which is more conducive to tumor metastasis and growth (43). Among the myeloid progenitors cells located in the TME, myeloid-derived suppressor cells (MDSCs), mast cells and most TAMs play key roles in promoting tumor development (44). MDSCs are immunosuppressive precursors of DCs, macrophages and granulocytes $(35,45)$. MDSCs maintain a normal tissue dynamic balance in response to a variety of systemic infections and injuries (33). Several animal models have demonstrated that MDSCs can promote tumor angiogenesis and disrupt the main mechanisms of immune surveillance by interfering with antigen presentation, T-cell activation and NK cell killing of DCs $(46,47)$. It has also been reported that mast cells are recruited into the tumor, where they release factors that promote endothelial cell proliferation to promote tumor angiogenesis (48-50). Increasing evidence suggests that microenvironment-mediated external stimulation plays a key role in tumor cell survival and drug resistance $(28,51)$. The complexity of the TME makes it difficult for the traditional oncolytic virus to reverse the conditions set by the TME while targeting tumor cells $(27,52)$. The traditional oncolytic virus can only inhibit the growth of tumor cells to a certain extent.

Owing to the constant improvement of genetic engineering techniques, it is getting easier to develop oncolytic adenovirus constructs with required properties. Preclinical trials involve wild-type and recombinant oncolytic adenovirus (Table I), aimed to reverse the TME while suppressing tumor cells (6,53) (Fig. 2). Several oncolytic adenoviruses are currently undergoing clinical trials as antitumor agents, and notably some progress has been made in reversing the TME (Table II). An ongoing clinical trial is testing RGD (Delta-24-rgd), a genetically modified oncolytic adenovirus, as an agent against glioma. The first results obtained in the phase I trials indicate that $20 \%$ of patients showed durable responses and $\mathrm{CD}^{+} \mathrm{T}$ cells infiltrated the tumor in large quantities (54). TILT-123 in preclinical studies altered the cytokine balance in the TME towards Th1 and resulted in a significant increase of the survival rate in severe combined immunodeficiency (SCID) mice with human tumors $(55,56)$. The currently ongoing phase I trial is recruiting patients with solid tumors to evaluate the safety.

\section{Adenovirus modification combined with immune cells in the TME}

DCs. DCs are derived from the bone marrow and play a key role in inducing and maintaining antitumor immunity $(57,58)$. Infiltration of mature DCs into the tumor can enhance immune activation and increase the recruitment of antitumor immune effector cells and pathways $(58,59)$. However, in the TME, the antigen-presenting function of DCs may be lost or inefficient (60). Tumor cells can inhibit the function of DCs or change the TME by recruiting immunosuppressive DCs (61). CD40 is a member of the tumor necrosis factor receptor family and is expressed in DCs, which is a target for infiltrating T cells (62). CD40L is instantaneously expressed in $\mathrm{T}$ cells, which activates the maturation of DCs and triggers the immune response. Adenovirus delivery of CD40L induces DC activation, thereby inducing a Th1 immune response (63). The oncolytic virus restricts CD40L expression in cancer cells, thus decreasing systemic exposure and weakening the systemic immune response $(64,65)$. Currently, there are already two phase I/II clinical trials involving LOAd703 that are recruiting patients. One of the studies is recruiting patients with pancreatic cancer to evaluate whether it supports the current treatment standards for pancreatic cancer and whether it can improve the survival rate of patients. Another study recruited patients with malignant melanoma and monitored their tumor response, immune response, virus shedding and survival rate. One of the major virulence factors of bacteria was Helicobacter pylori neutrophil-activating protein (HP-NAP), which is a TLR-2 agonist capable of chemotaxis of neutrophils, and monocytes and stimulates them to produce reactive oxygen species $(66,67)$. HP-NAP also induced 


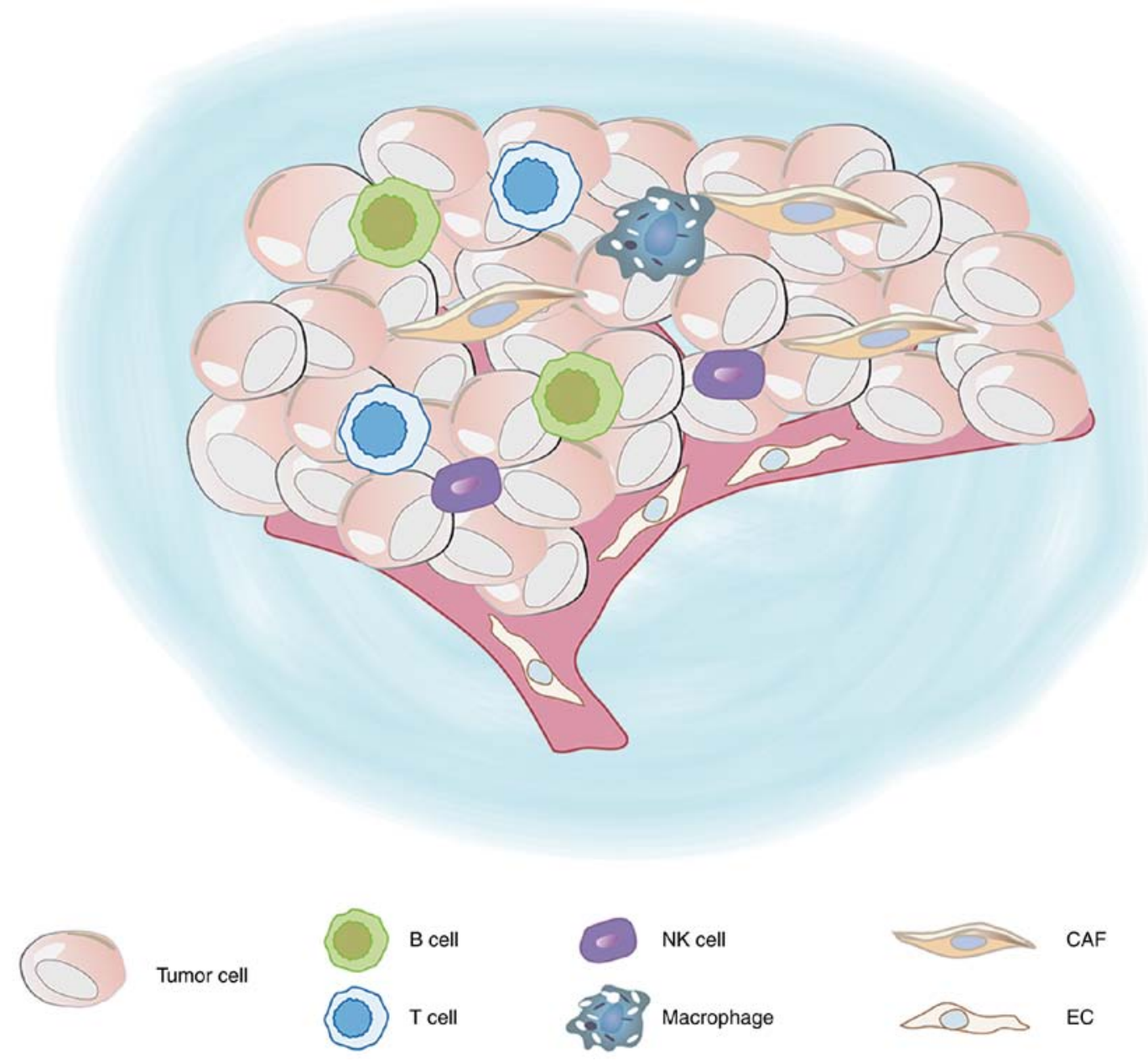

Figure 1. Schematic diagram of the tumor microenvironment.

Th1-polarized immune responses by stimulating the secretion of interleukin (IL)-12 and IL-23 and other pro-inflammatory cytokines such as tumor necrosis factor (TNF)- $\alpha$ and IL-8 (68). Ag-presenting-HP-NAP-activated DCs effectively amplified Ag specific T cells, an important characteristic of mature DCs (69). HP-NAP-activated DCs resulted in Th1 cytokine secretion, with high IL-12 expression, relatively low IL-10 secretion and migrated to CCL19 (69).

Macrophages. TAMs are divided into specific M1-like macrophage subsets and specific M2-like macrophage subsets, and M1-like macrophage subsets are activated by the classical pathway and exert notable antitumor effects $(70,71)$. In the TME, specific M2-like macrophage subsets are the most common, and their cytokines IL-6, TNF, IL-1 and IL-23 promote tumor growth and metastasis and silence T-cell function (72,73). Selective removal of specific M2-like macrophage subsets has become a research hotspot. Granulocyte-macrophage colony-stimulating factor (GM-CSF) can affect macrophages, promote their rapid differentiation to mature macrophages, prolong the life of mature macrophages, and enhance their cellular immune function (74). By inserting GM-CSF into the Ad5 vector, ONCS-102 induced notable antitumor immunity (75). ONCOS-102 is currently being assessed in two phase I clinical trials in advanced peritoneal malignancies and malignant pleural mesothelioma. Ad-CD-GMCSF is an adenovirus carrying cytomegalovirus promoter cytosine deaminase (CD) and GM-CSF (75). Adenovirus vectors expressing CD and GM-CSF are well tolerated in refractory tumors (5). CD47 is a cell surface transmembrane protein present in normal tissues (76). It is highly expressed in malignant tumor cells and binds to signaling regulatory protein- $\alpha$ (SIRP $\alpha)$ expressed on macrophages to inhibit macrophage phagocytosis, resulting in immune escape. SIRP $\alpha$-FC fusion protein inserted into the oncolytic adenovirus vector blocks the binding of CD47 to macrophages, leading to a large increase in macrophage infiltration in tumor tissues, thus enhancing the antitumor effect (77). MMAD-IL13 loaded with IL13 demonstrated enhanced antitumor effects by inducing apoptosis in the TME in vivo, and decreased the percentage of specific M2-like macrophages (78). Scott et al (79) constructed a set of bivalent and trivalent T-cell adapters (BiTEs/TriTEs), which can specifically recognize CD3 $\varepsilon$ on $\mathrm{T}$ cells and the folate receptor or CD206 on specific M2-like macrophages. T-cell adapters were used to specifically direct the cytotoxicity of endogenous T cells to M2-like macrophages and deplete M2-like macrophages in tumor tissues. There was a significant increase in specific M1-like macrophage fraction among surviving macrophages, indicating a reversal of macrophage type in the TME (79).

$N K s$. NK cells have a notable antitumor effect in the initial stages of tumors, which can eliminate tumor cells (30). However, at the 
Table I. Partial oncolytic adenovirus trials to reverse the tumor microenvironment.

\begin{tabular}{|c|c|c|c|c|}
\hline Oncolytic adenovirus & Gene modification & Target cells in TME & Target tumor cells & (Refs.) \\
\hline Ad3-hTERT-CMV-hCD40L & $\mathrm{CD} 40 \mathrm{~L}$ & DCs & A549 & (64) \\
\hline LOAd703 & CD40L & DCs & A549 & $(65)$ \\
\hline Ad5 [i/ppt-sNAP] & HP-NAP & DCs & $\mathrm{LNCaP}$ & (69) \\
\hline ONCOS-102 & GM-CSF & Macrophages, $\mathrm{CD}^{+} \mathrm{T}$ cells & $\mathrm{AB} 12$ & (75) \\
\hline Ad-CD-GMCSF & GM-CSF & Macrophages, $\mathrm{CD} 8^{+} \mathrm{T}$ cells & Colon cancer cell line & (5) \\
\hline SG635-SF & $\begin{array}{l}\text { A signal regulatory } \\
\text { protein- } \alpha(\mathrm{SIRP} \alpha)-\operatorname{IgG} 1 \\
\text { Fc fusion gene }\end{array}$ & Macrophages & SK-OV3, HO8910 & (77) \\
\hline MMAD-IL-13 & IL-13 & Macrophages & Cal-27, SCC-4, Tca8113 & (78) \\
\hline EnAd & BiTEs/TriTEs & Macrophages & DLD-1 & (79) \\
\hline Ad-CCL21-IL21 & CCL21 & DCs & PC-3M, THP-1, HeLa, Caco-2 & (82) \\
\hline Ad-CCL21-IL21 & IL-21 & NK cells & PC-3M, THP-1, HeLa, Caco-2 & (82) \\
\hline Ad-E2F/IL15 & IL-15 & NK cells, $\mathrm{CD} 8^{+} \mathrm{T}$ cells & $\begin{array}{l}\text { U87MG, BGC823, SW620, } \\
\text { HCT116 }\end{array}$ & (84) \\
\hline ICO15K-FBiTE & FBiTE & CAFs, T cells & HT1080, A549 & (53) \\
\hline AdCEAp-miR126/34a & miR-126, miR-34a & Vascular endothelial cells & Pancreatic adenocarcinoma & (96) \\
\hline VEGF-CRAd & VEGF & Vascular endothelial cells & $\begin{array}{l}\text { NCI-H28, NCI-H226, } \\
\text { NCI-H20, NCI-H2452, } \\
\text { MSTO-211H }\end{array}$ & (97) \\
\hline SKL002 & CTLA4 & $\mathrm{T}$ cells & $\begin{array}{l}\text { HepG2, A549, Lovo, HeLa, } \\
\text { HCT116, SW780 }\end{array}$ & (106) \\
\hline Ad5-PC & PD-1 & $\mathrm{CD} 8^{+} \mathrm{T}$ cells & $\begin{array}{l}\text { HCC-LM3, H22, Hepa1-6, } \\
\text { A549, B16-F10, LLC1 }\end{array}$ & (105) \\
\hline
\end{tabular}

TME, tumor microenvironment; DCs, dendritic cells; NK, natural killer; CAFs, cancer-associated fibroblasts.

advanced tumor stage, NK cells gradually lose their antitumor ability and become dysfunctional (80). IL-21 is involved in NK cell differentiation (81), and the oncolytic adenovirus equipped with IL-21 exerts an obvious inhibitory effect on the proliferation of tumor cells (82). Similarly, NK cells can be activated by IL-15 (83), and oncolytic adenovirus (Ad-E2F/IL15), which expresses IL-15, can lyse tumor cells and coordinate with immune cells to enhance the antitumor response (84).

\section{Adenovirus modification combined with stromal cells in the TME}

Cancer-associated fibroblasts (CAFs). CAFs are a major component of the tumor stroma, which regulate the TME and influence the behavior of tumor cells, and play crucial roles in the occurrence, development, invasion and metastasis of tumors $(85,86)$. Fibroblasts in the TME secrete growth factors such as hepatocyte growth factor, fibroblast growth factor and CXCL12 (87), which promote the growth and survival of malignant cells, and act as chemokines to induce the migration of other cells into the TME $(88,89)$. Concurrently, CAFs form a barrier in tumors and prevent the effective penetration and transmission of oncolytic virus, thus limiting its efficacy $(90,91)$. By modifying oncolytic adenovirus, the effects of tumor cells and CAFs will be inhibited at the same time (92). Fibroblast activation protein- $\alpha$ (FAP) is highly expressed in CAFs. The FAP single-chain antibody is linked to an anti-human $\mathrm{CD} 3$ single-chain variable region ( $\mathrm{scFv}$ ) and loaded into oncolytic adenovirus. FAP scFv, while specifically recognizing and targeting CAFs, activates $\mathrm{T}$ cells and enhances T-cell-mediated cytotoxic effects on tumor-associated fibroblasts, thus weakening the cell barrier caused by CAFs and enhancing oncolytic activity $(24,53)$.

Vascular endothelial cells. Blood vessels play a vital role in the development of tumors, providing nutrition and metastasis channels for tumor cells (93). The phenotype of vascular endothelial cells changes in the TME. Tumor cells secrete vascular endothelial growth factor (VEGF) and other endothelial growth factors to promote the generation of tumor neovascularization (94). Given that the downstream target gene of microRNA (miRNA/miR)-126 is VEGF (95), miR-126 is loaded into the oncolytic adenovirus, namely ADCEAP-miR126/34A, which decreases the generation of tumor blood vessels (96). Concurrently, the VEGF promoter is inserted into the adenovirus vector, targeting the tumor vascular endothelial cells via the same mechanism of action enhancing the oncolysis of adenovirus (97). IL-24 is a tumor suppressor molecule with broad-spectrum antitumor activity (98). It inhibits the growth of tumor cells by inhibiting tumor angiogenesis (99). A previous study has demonstrated that while expressing IL24, CRAd-IL24 significantly increased the release of virus particles and enhanced their antitumor effect (6). 


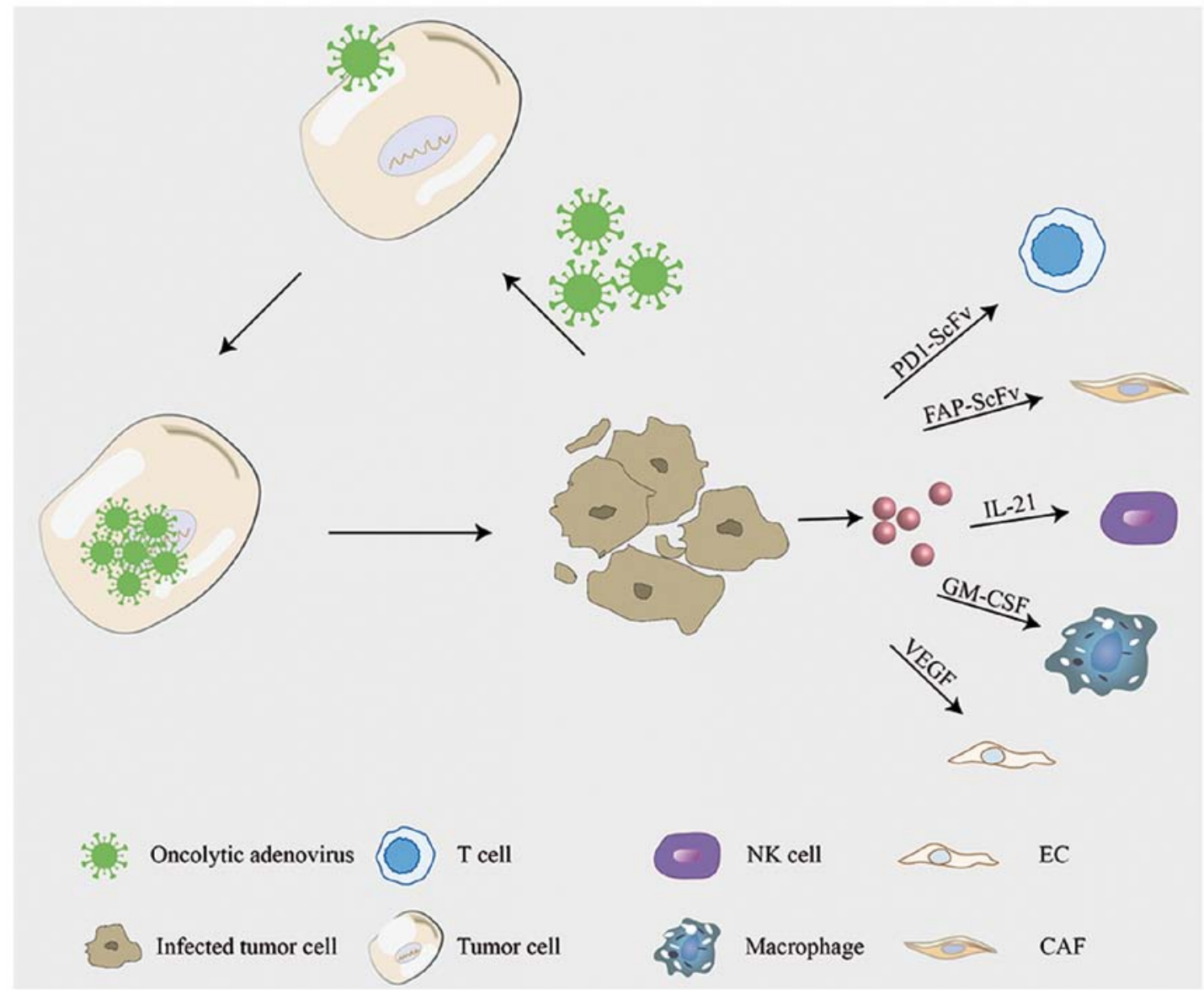

Figure 2. Oncolytic adenovirus mechanism of action. When the oncolytic adenovirus specifically infects tumor cells, it releases new virus particles and transmits them to other tumor cells. It also delivers cytokines, growth factors, fusion proteins and other substances that act on other corresponding cells in the tumor microenvironment.

\section{Adenovirus modification combined with immune checkpoints in the TME}

Checkpoint molecules are regulatory molecules that play an inhibitory role in the immune system and are critical to maintain tolerance, prevent an autoimmune response and minimize tissue damage by controlling the timing and intensity of the immune response $(100,101)$. The expression of immunological checkpoint molecules on immune cells suppresses the immune cell function as the host fails to produce an effective antitumor immune response. There are numerous receptors on tumorigenic immune escape $\mathrm{T}$ cells, including co-stimulatory signal receptors that can stimulate T-cell proliferation, and co-inhibitory signal receptors that can inhibit T-cell proliferation (102). Immune checkpoint molecules are predominantly inhibitory molecules, in which the immune checkpoint on $T$ cells suppresses the immune function of T cells, causing tumor escape (103). However, the clinical benefits of monotherapy with immune checkpoint inhibitors, such as anti-programmed death-1 antibody, are limited to small populations (104). Zhang et al (105) designed an adenovirus (Ad5-PC) to express a soluble fusion protein (programmed cell death protein $1 / \mathrm{CD} 137 \mathrm{~L}$ ), which significantly increased the number of T lymphocytes in the TME and effectively improved the survival rate of tumor-bearing mice (105). After loading anti-cytotoxic T lymphocyte-associated antigen-4 (CTLA-4) antibody into the adenovirus vector, tumor cells were infected.
CTLA-4 antibody was significantly expressed in tumor cells and its antitumor activity was significantly enhanced (106). Ad5/3- $\Delta 24 \mathrm{aCTLA} 4$ can express CTLA-4 human intact monoclonal antibody, and in the normal donors and patients with advanced solid tumors in the peripheral blood mononuclear cells that were tested (107). Ad5/3- $\Delta 24 \mathrm{aCTLA} 4$ significantly enhanced the immune response and activated the pro-apoptotic effect of T cells (107).

\section{Outlook}

Recently, the transformation technology of oncolytic adenoviruses has significantly progressed. However, increasing evidence suggest concerns about the tumor-promoting effect of the TME. Thus, the transformation of oncolytic viruses into TME has become a research hot spot; however, the in vitro simulation of the TME does not accurately reflect the human microenvironment. Cytokines and growth factors were added to the cell culture, either co-cultured with tumor cells and other cells, or with three-dimensional scaffoldings to simulate the TME. However, due to the complexity of the TME, it remains difficult to completely simulate the human TME completely in vitro. Currently, xenotransplantation of immunodeficient mice is the most commonly used animal experimental method for studying human tumors. Briefly, human tumor cells are inserted into mice; however, this fails 
Table II. Clinical trials of oncolytic adenoviruses affecting the tumor microenvironment (Jan. 2021, ClinicalTrials.gov).

\begin{tabular}{|c|c|c|c|c|}
\hline Trial number & Oncolytic adenovirus & Study title & Target & Phase \\
\hline NCT01582516 & Delta-24-rgd & $\begin{array}{l}\text { Safety Study of Replication-competent } \\
\text { Adenovirus (Delta-24-rgd) in Patients With } \\
\text { Recurrent Glioblastoma }\end{array}$ & Recurrent glioblastoma & I, II \\
\hline NCT04695327 & TILT-123 & $\begin{array}{l}\text { TNF } \alpha \text { and IL-2 Coding Oncolytic Adenovirus } \\
\text { TILT- } 123 \text { Monotherapy (TUNIMO) }\end{array}$ & Solid tumor & I \\
\hline NCT04217473 & TILT-123 & $\begin{array}{l}\text { TNFalpha and Interleukin } 2 \text { Coding Oncolytic } \\
\text { Adenovirus TILT-123 During TIL Treatment of } \\
\text { Advanced Melanoma (TUNINTIL) }\end{array}$ & Advanced melanoma & I \\
\hline NCT02705196 & LOAd703 & $\begin{array}{l}\text { LOAd703 Oncolytic Virus Therapy for } \\
\text { Pancreatic Cancer }\end{array}$ & Pancreatic cancer & I, II \\
\hline NCT04123470 & LOAd703 & $\begin{array}{l}\text { A Phase I/II Trial Investigating LOAd703 in } \\
\text { Combination With Atezolizumab in Malignant } \\
\text { Melanoma }\end{array}$ & Malignant melanoma & I, II \\
\hline NCT03514836 & ONCOS-102 & $\begin{array}{l}\text { A Phase I/II, Safety Clinical Trial of } \\
\text { DCVAC/PCa and ONCOS-102 in Men With } \\
\text { Metastatic Castration-resistant Prostate Cancer }\end{array}$ & Prostate cancer & I, II \\
\hline NCT02963831 & ONCOS-102 & $\begin{array}{l}\text { A Phase } 1 / 2 \text { Study to Investigate the Safety, } \\
\text { Biologic and Anti-tumor Activity of ONCOS-102 } \\
\text { in Combination With Durvalumab in Subjects } \\
\text { With Advanced Peritoneal Malignancies }\end{array}$ & $\begin{array}{l}\text { Advanced peritoneal } \\
\text { malignancies }\end{array}$ & $\mathrm{I}, \mathrm{II}$ \\
\hline NCT04053283 & NG-641 & $\begin{array}{l}\text { First in Human Study With NG-641, an } \\
\text { Oncolytic Transgene Expressing Adenoviral } \\
\text { Vector }\end{array}$ & $\begin{array}{l}\text { Metastatic or advanced } \\
\text { epithelial tumours }\end{array}$ & I \\
\hline NCT03852511 & NG-350A & $\begin{array}{l}\text { First in Human Study of NG-350A (an } \\
\text { Oncolytic Adenoviral Vector Which Expresses } \\
\text { an Anti-CD } 40 \text { Antibody) (FORTITUDE) }\end{array}$ & $\begin{array}{l}\text { Metastatic or advanced } \\
\text { epithelial cancer }\end{array}$ & I \\
\hline NCT04097002 & ORCA-010 & $\begin{array}{l}\text { First in Man Clinical Study to Evaluate Safety } \\
\text { and Tolerability of an Oncolytic Adenovirus in } \\
\text { Prostate Cancer Patients. }\end{array}$ & Prostate cancer & I, II \\
\hline
\end{tabular}

to fully reflect the human TME. Several factors affect the oncolytic effect of an oncolytic virus. The strong immune response and severe cytokine storm when the virus first enters the host may be fatal. Subsequent challenges arise at later stages during elimination of oncolytic virus by the immune system of the host. It is hypothesized that the selection of oncolytic viruses will be the focus of future research, and it will be individualized, with the intent that the oncolytic virus most suitable for each patient can be selected, based on the characteristics of the tumor cells and the TME.

\section{Acknowledgements}

Not applicable.

\section{Funding}

This review was funded by Programs for the National Natural Scientific Foundation of China (grant no. 81430035), the Major National Science and Technology Projects-Major New Drug Creation (grant no. 2019ZX09301-132), the Changjiang
Scholars and Innovative Research Team in University (grant no. IRT_15R13), and the Guangxi Science and Technology Base and Talent Special Project (grant no. AD17129003).

\section{Availability of data and materials}

Not applicable.

\section{Authors' contributions}

$\mathrm{XW}$ and YZ conceived the subject of the review. LZ designed the review. XW wrote the manuscript, performed the literature research as well as interpreted the relevant literature, and prepared the figures. LZ analyzed the review critically for important intellectual content. XW and LZ edited and revised the manuscript. All authors have read and approved the final manuscript.

\section{Ethics approval and consent to participate}

Not applicable. 


\section{Patient consent for publication}

Not applicable.

\section{Competing interests}

The authors declare that they have no competing interests.

\section{References}

1. Giraldo NA, Sanchez-Salas R, Peske JD, Vano Y, Becht E, Petitprez F, Validire P, Ingels A, Cathelineau X, Fridman WH and Sautès-Fridman C: The clinical role of the TME in solid cancer. Br J Cancer 120: 45-53, 2019.

2. Chen Y, Liu J, Wang W, Xiang L, Wang J, Liu S, Zhou H and Guo Z: High expression of hnRNPA1 promotes cell invasion by inducing EMT in gastric cancer. Oncol Rep 39: 1693-1701, 2018

3. Choi J, Gyamfi J, Jang H and Koo JS: The role of tumor-associated macrophage in breast cancer biology. Histol Histopathol 33 133-145, 2018.

4. Sun Y: Tumor microenvironment and cancer therapy resistance. Cancer Lett 380: 205-215, 2016.

5. Akbulut H, Coleri A, Sahin G, Tang Y and Icli F: A bicistronic adenoviral vector carrying cytosine deaminase and granulocyte-macrophage colony-stimulating factor increases the therapeutic efficacy of cancer gene therapy. Hum Gene Ther 30: 999-1007, 2019.

6. Ashshi AM, El-Shemi AG, Dmitriev IP, Kashentseva EA and Curiel DT: Combinatorial strategies based on CRAd-IL24 and CRAd-ING4 virotherapy with anti-angiogenesis treatment for ovarian cancer. J Ovarian Res 9: 38, 2016.

7. Athanasopoulos T, Munye MM and Yanez-Munoz RJ: Nonintegrating gene therapy vectors. Hematol Oncol Clin North Am 31: 753-770, 2017

8. Salzman R, Cook F, Hunt T, Malech HL, Reilly P, Foss-Campbell B and Barrett D: Addressing the value of gene therapy and enhancing patient access to transformative treatments. Mol Ther 26: 2717-2726, 2018.

9. Stasiak AC and Stehle T: Human adenovirus binding to host cell receptors: A structural view. Med Microbiol Immunol 209: 325-333, 2020.

10. Greber UF and Flatt JW: Adenovirus entry: From infection to immunity. Annu Rev Virol 6: 177-197, 2019.

11. Hoeben RC and Uil TG: Adenovirus DNA replication. Cold Spring Harb Perspect Biol 5: a013003, 2013.

12. Gao J,Zhang W and Ehrhardt A: Expanding the spectrum of adenoviral vectors for cancer therapy. Cancers (Basel) 12: 1139, 2020.

13. Ip WH and Dobner T: Cell transformation by the adenovirus oncogenes E1 and E4. FEBS Lett 594: 1848-1860, 2020.

14. Bradley RR, Maxfield LF, Lynch DM, Iampietro MJ, Borducchi EN and Barouch DH: Adenovirus serotype 5-specific neutralizing antibodies target multiple hexon hypervariable regions. J Virol 86: 1267-1272, 2012.

15. Niemann J and Kuhnel F: Oncolytic viruses: Adenoviruses Virus Genes 53: 700-706, 2017.

16. Machitani M, Katayama K, Sakurai F, Matsui H, Yamaguchi T, Suzuki T, Miyoshi H, Kawabata K and Mizuguchi H: Development of an adenovirus vector lacking the expression of virus-associated RNAs. J Control Release 154: 285-289, 2011.

17. Zheng Y, Stamminger T and Hearing P: E2F/Rb family proteins mediate interferon induced repression of adenovirus immediate early transcription to promote persistent viral infection. PLoS Pathog 12: e1005415, 2016.

18. Yamauchi S, Zhong B, Kawamura K, Yang S, Kubo S, Shingyoji M, Sekine I, Tada Y, Tatsumi K, Shimada H, et al: Cytotoxicity of replication-competent adenoviruses powered by an exogenous regulatory region is not linearly correlated with the viral infectivity/gene expression or with the E1A-activating ability but is associated with the p53 genotypes. BMC Cancer 17: 622, 2017.

19. Cervera-Carrascon V, Quixabeira DCA, Havunen R, Santos JM, Kutvonen E, Clubb JHA, Siurala M, Heiniö C, Zafar S, Koivula T, et al: Comparison of clinically relevant oncolytic virus platforms for enhancing T cell therapy of solid tumors. Mol Ther Oncolytics 17: 47-60, 2020.

20. Huang H, Liu Y, Liao W, Cao Y, Liu Q, Guo Y, Lu Y and Xie Z: Oncolytic adenovirus programmed by synthetic gene circuit for cancer immunotherapy. Nat Commun 10: 4801, 2019.
21. Rosewell Shaw A and Suzuki M: Recent advances in oncolytic adenovirus therapies for cancer. Curr Opin Virol 21: 9-15, 2016.

22. Ran L, Tan X, Li Y, Zhang H, Ma R, Ji T, Dong W, Tong T, Liu Y, Chen $\mathrm{D}$, et al: Delivery of oncolytic adenovirus into the nucleus of tumorigenic cells by tumor microparticles for virotherapy. Biomaterials 89: 56-66, 2016.

23. Tazawaa H, Kagawab S and Fujiwarab T: Oncolytic adenovirus-induced autophagy: Tumor-suppressive effect and molecular basis. Acta Med Okayama 67: 333-342, 2013.

24. Freedman JD, Duffy MR, Lei-Rossmann J, Muntzer A, Scott EM, Hagel J, Campo L, Bryant RJ, Verrill C, Lambert A, et al: An oncolytic virus expressing a T-cell engager simultaneously targets cancer and immunosuppressive stromal cells. Cancer Res 78: 6852-6865, 2018.

25. Jung KH, Choi IK, Lee HS, Yan HH, Son MK, Ahn HM, Hong J, Yun CO and Hong SS: Oncolytic adenovirus expressing relaxin (YDC002) enhances therapeutic efficacy of gemcitabine against pancreatic cancer. Cancer Lett 396: 155-166, 2017.

26. Yokoda RT, Nagalo BM and Borad MJ: Oncolytic adenoviruses in gastrointestinal cancers. Biomedicines 6: 33, 2018.

27. Quail DF and Joyce JA: Microenvironmental regulation of tumor progression and metastasis. Nat Med 19: 1423-1437, 2013.

28. Belli C, Trapani D, Viale G, D'Amico P, Duso BA, Della Vigna P, Orsi $\mathrm{F}$ and Curigliano $\mathrm{G}$ : Targeting the microenvironment in solid tumors. Cancer Treat Rev 65: 22-32, 2018.

29. Zhong S, Jeong JH, Chen Z, Chen Z and Luo JL: Targeting tumor microenvironment by small-molecule inhibitors. Transl Oncol 13: 57-69, 2020.

30. Terren I, Orrantia A, Vitalle J, Zenarruzabeitia O and Borrego F: NK cell metabolism and tumor microenvironment. Front Immunol 10: 2278, 2019.

31. Maimela NR, Liu S and Zhang Y: Fates of $\mathrm{CD} 8^{+} \mathrm{T}$ cells in tumor microenvironment. Comput Struct Biotechnol J 17: 1-13, 2018.

32. Najafi M, Farhood B and Mortezaee K: Extracellular matrix (ECM) stiffness and degradation as cancer drivers. J Cell Biochem 120: 2782-2790, 2019

33. Guo S and Deng CX: Effect of stromal cells in tumor microenvironment on metastasis initiation. Int J Biol Sci 14: 2083-2093, 2018.

34. Jang I and Beningo KA: Integrins, CAFs and mechanical forces in the progression of cancer. Cancers (Basel) 11: 721, 2019.

35. Jarosz-Biej M, Smolarczyk R, Cichon T and Kulach N: Tumor microenvironment as A 'Game Changer' in cancer radiotherapy. Int J Mol Sci 20: 3212, 2019.

36. Nishide S, Uchida J, Matsunaga S, Tokudome K, Yamaguchi T, Kabei K, Moriya T, Miura K, Nakatani T and Tomita S: Prolyl-hydroxylase inhibitors reconstitute tumor blood vessels in mice. J Pharmacol Sci 143: 122-126, 2020.

37. Carretero R, Sektioglu IM, Garbi N, Salgado OC, Beckhove P and Hammerling GJ: Eosinophils orchestrate cancer rejection by normalizing tumor vessels and enhancing infiltration of CD8(+) T cells. Nat Immunol 16: 609-617, 2015.

38. Zhao H, Tian X, He L, Li Y, Pu W, Liu Q, Tang J, Wu J, Cheng X, Liu Y, et al: $\mathrm{Apj}^{+}$vessels drive tumor growth and represent a tractable therapeutic target. Cell Rep 25: 1241-1254.e5, 2018.

39. Brand A, Singer K, Koehl GE, Kolitzus M, Schoenhammer G, Thiel A, Matos C, Bruss C, Klobuch S, Peter K, et al: LDHA-Associated lactic acid production blunts tumor immunosurveillance by T and NK cells. Cell Metab 24: 657-671, 2016.

40. Fischer K, Hoffmann P, Voelkl S, Meidenbauer N, Ammer J, Edinger M, Gottfried E, Schwarz S, Rothe G, Hoves S, et al: Inhibitory effect of tumor cell-derived lactic acid on human $\mathrm{T}$ cells. Blood 109: 3812-3819, 2007.

41. Colegio OR, Chu NQ, Szabo AL, Chu T, Rhebergen AM, Jairam V, Cyrus N, Brokowski CE, Eisenbarth SC, Phillips GM, et al: Functional polarization of tumour-associated macrophages by tumour-derived lactic acid. Nature 513: 559-563, 2014.

42. Ohashi T, Aoki M, Tomita H, Akazawa T, Sato K, Kuze B, Mizuta K, Hara A, Nagaoka H, Inoue $\mathrm{N}$ and Ito Y: M2-like macrophage polarization in high lactic acid-producing head and neck cancer. Cancer Sci 108: 1128-1134, 2017.

43. Urbanska $\mathrm{K}$ and Orzechowski A: Unappreciated role of LDHA and LDHB to control apoptosis and autophagy in tumor cells. Int J Mol Sci 20: 2085, 2019.

44. Fleming V, Hu X, Weber R, Nagibin V, Groth C, Altevogt P, Utikal J and Umansky V: Targeting myeloid-derived suppressor cells to bypass tumor-induced immunosuppression. Front Immunol 9: 398, 2018.

45. Hinshaw DC and Shevde LA: The tumor microenvironment innately modulates cancer progression. Cancer Res 79: 4557-4566, 2019 . 
46. Safarzadeh E, Orangi M, Mohammadi H, Babaie F and Baradaran B: Myeloid-derived suppressor cells: Important contributors to tumor progression and metastasis. J Cell Physiol 233: 3024-3036, 2018.

47. Dysthe $M$ and Parihar R: Myeloid-Derived suppressor cells in the tumor microenvironment. Adv Exp Med Biol 1224: 117-140, 2020

48. Ribatti D, Tamma R and Crivellato E: Cross talk between natural killer cells and mast cells in tumor angiogenesis. Inflamm Res 68: 19-23, 2019.

49. Albini A, Bruno A, Noonan DM and Mortara L: Contribution to tumor angiogenesis from innate immune cells within the tumor microenvironment: Implications for immunotherapy. Front Immunol 9: 527, 2018.

50. Kabiraj A, Jaiswal R, Singh A, Gupta J, Singh A and Samadi FM: Immunohistochemical evaluation of tumor angiogenesis and the role of mast cells in oral squamous cell carcinoma. J Cancer Res Ther 14: 495-502, 2018.

51. Shee K, Yang W,Hinds JW,Hampsch RA, Varn FS, Traphagen NA, Patel K, Cheng C, Jenkins NP, Kettenbach AN, et al: Therapeutically targeting tumor microenvironment-mediated drug resistance in estrogen receptor-positive breast cancer. J Exp Med 215: 895-910, 2018.

52. Binnewies M, Roberts EW, Kersten K, Chan V, Fearon DF, Merad M, Coussens LM, Gabrilovich DI, Ostrand-Rosenberg S, Hedrick CC, et al: Understanding the tumor immune microenvironment (TIME) for effective therapy. Nat Med 24: 541-550, 2018.

53. de Sostoa J, Fajardo CA, Moreno R, Ramos MD, Farrera-Sal M and Alemany R: Targeting the tumor stroma with an oncolytic adenovirus secreting a fibroblast activation protein-targeted bispecific T-cell engager. J Immunother Cancer 7: 19, 2019.

54. Lang FF, Conrad C, Gomez-Manzano C, Yung WKA, Sawaya R, Weinberg JS, Prabhu SS, Rao G, Fuller GN, Aldape KD, et al: Phase I Study of DNX-2401 (Delta-24-RGD) Oncolytic Adenovirus: Replication and immunotherapeutic effects in recurrent malignant glioma. J Clin Oncol 36: 1419-1427, 2018.

55. Havunen R, Siurala M, Sorsa S, Grönberg-Vähä-Koskela $S$, Behr M, Tähtinen S, Santos JM, Karell P, Rusanen J, Nettelbeck DM, et al: Oncolytic adenoviruses armed with tumor necrosis factor alpha and interleukin-2 enable successful adoptive cell therapy. Mol Ther Oncolytics 4: 77-86, 2016.

56. Santos JM, Cervera-Carrascon V, Havunen R, Zafar S, Siurala M, Sorsa S, Anttila M, Kanerva A and Hemminki A: Adenovirus coding for interleukin-2 and tumor necrosis factor alpha replaces lymphodepleting chemotherapy in adoptive T cell therapy. Mol Ther 26: 2243-2254, 2018.

57. Lee YS and Radford KJ: The role of dendritic cells in cancer. Int Rev Cell Mol Biol 348: 123-178, 2019.

58. Palucka K and Banchereau J: Cancer immunotherapy via dendritic cells. Nat Rev Cancer 12: 265-277, 2012

59. Parnas O, Jovanovic M, Eisenhaure TM, Herbst RH, Dixit A, Ye CJ, Przybylski D, Platt RJ, Tirosh I, Sanjana NE, et al: A genome-wide CRISPR screen in primary immune cells to dissect regulatory networks. Cell 162: 675-686, 2015.

60. Oh DS and Lee HK: Autophagy protein ATG5 regulates CD36 expression and anti-tumor MHC class II antigen presentation in dendritic cells. Autophagy 15: 2091-2106, 2019.

61. Chen L, Hasni MS, Jondal M and Yakimchuk K: Modification of anti-tumor immunity by tolerogenic dendritic cells. Autoimmunity 50: 370-376, 2017.

62. Karnell JL, Rieder SA, Ettinger R and Kolbeck R: Targeting the CD40-CD40L pathway in autoimmune diseases: Humoral immunity and beyond. Adv Drug Deliv Rev 141: 92-103, 2019.

63. Vitale LA, Thomas LJ, He LZ, O'Neill T, Widger J, Crocker A, Sundarapandiyan K, Storey JR, Forsberg EM, Weidlick J, et al: Development of CDX-1140, an agonist CD40 antibody for cancer immunotherapy. Cancer Immunol Immunother 68: 233-245, 2019.

64. Zafar S, Sorsa S, Siurala M, Hemminki O, Havunen R, Cervera-Carrascon V, Santos JM, Wang H, Lieber A, De Gruijl T, et al: CD40L coding oncolytic adenovirus allows long-term survival of humanized mice receiving dendritic cell therapy. Oncoimmunology 7: e1490856, 2018.

65. Eriksson E, Milenova I, Wenthe J, Moreno R, Alemany R and Loskog A: IL-6 signaling blockade during CD40-mediated immune activation favors antitumor factors by reducing TGF- $\beta$, collagen type I, and PD-L1/PD-1. J Immunol 202: 787-798, 2019.

66. Guo X, Ding C, Lu J, Zhou T, Liang T, Ji Z, Xie P, Liu X and Kang Q: HP-NAP ameliorates OXA-induced atopic dermatitis symptoms in mice. Immunopharmacol Immunotoxicol 42: $416-422,2020$
67. Codolo G, Fassan M, Munari F, Volpe A, Bassi P, Rugge M, Pagano F, D'Elios MM and de Bernard M: HP-NAP inhibits the growth of bladder cancer in mice by activating a cytotoxic Th1 response. Cancer Immunol Immunother 61: 31-40, 2012.

68. D'Elios MM, Amedei A, Cappon A, Del Prete G and de Bernard M: The neutrophil-activating protein of Helicobacter pylori (HP-NAP) as an immune modulating agent. FEMS Immunol Med Microbiol 50: 157-164, 2007.

69. Ramachandran M, Jin C, Yu D, Eriksson F and Essand M: Vector-encoded Helicobacter pylori neutrophil-activating protein promotes maturation of dendritic cells with Th1 polarization and improved migration. J Immunol 193: 2287-2296, 2014

70. Mantovani A, Marchesi F, Malesci A, Laghi L and Allavena P: Tumour-associated macrophages as treatment targets in oncology. Nat Rev Clin Oncol 14: 399-416, 2017.

71. Ubil E, Caskey L, Holtzhausen A, Hunter D, Story C and Earp HS: Tumor-secreted Pros1 inhibits macrophage M1 polarization to reduce antitumor immune response. J Clin Invest 128 2356-2369, 2018

72. Myers KV, Amend SR and Pienta KJ: Targeting Tyro3, Axl and MerTK (TAM receptors): Implications for macrophages in the tumor microenvironment. Mol Cancer 18: 94, 2019.

73. Huang YJ, Yang CK, Wei PL, Huynh TT, Whang-Peng J, Meng TC, Hsiao M, Tzeng YM, Wu AT and Yen Y: Ovatodiolide suppresses colon tumorigenesis and prevents polarization of M2 tumor-associated macrophages through YAP oncogenic pathways. J Hematol Oncol 10: 60, 2017.

74. Cho H, Seo Y, Loke KM, Kim SW, Oh SM, Kim JH, Soh J, Kim HS, Lee H, Kim J, et al: Cancer-Stimulated CAFs enhance monocyte differentiation and protumoral TAM activation via IL6 and GM-CSF secretion. Clin Cancer Res 24: 5407-5421, 2018

75. Kuryk L, Moller AW, Garofalo M, Cerullo V,Pesonen S, Alemany R and Jaderberg M: Antitumor-specific T-cell responses induced by oncolytic adenovirus ONCOS-102 (AdV5/3-D24-GM-CSF) in peritoneal mesothelioma mouse model. J Med Virol 90: 1669-1673, 2018.

76. Hayat SMG, Biancon V, Pirro M, Jaafari MR, Hatamipour M and Sahebkar A: CD47 role in the immune system and application to cancer therapy. Cell Oncol (Dordr.) 43: 19-30, 2020.

77. Huang Y, Lv SQ, Liu PY, Ye ZL, Yang H, Li LF, Zhu HL, Wang Y, Cui LZ, Jiang DQ, et al: A SIRP $\alpha-F c$ fusion protein enhances the antitumor effect of oncolytic adenovirus against ovarian cancer. Mol Oncol 14: 657-668, 2020.

78. Zhang KL, Li RP, Zhang BP, Gao ST, Li B, Huang CJ, Cao R, Cheng JY, Xie XD, Yu ZH and Feng XY: Efficacy of a new oncolytic adenovirus armed with IL-13 against oral carcinoma models. Onco Targets Ther 12: 6515-6523, 2019.

79. Scott EM, Jacobus EJ, Lyons B, Frost S, Freedman JD, Dyer A Khalique $\mathrm{H}$, Taverner WK, Carr A, Champion BR, et al: Bi- and tri-valent $\mathrm{T}$ cell engagers deplete tumour-associated macrophages in cancer patient samples. J Immunother Cancer 7: 320, 2019.

80. Yao C, Ni Z, Gong C, Zhu X, Wang L, Xu Z, Zhou C, Li S, Zhou W, Zou C and Zhu S: Rocaglamide enhances NK cell-mediated killing of non-small cell lung cancer cells by inhibiting autophagy. Autophagy 14: 1831-1844, 2018.

81. Davis MR, Zhu Z, Hansen DM, Bai Q and Fang Y: The role of IL-21 in immunity and cancer. Cancer Lett 358: 107-114, 2015.

82. Li Y, Li YF, Si CZ, Zhu YH, Jin Y, Zhu TT, Liu MY and Liu GY: CCL21/IL21-armed oncolytic adenovirus enhances antitumor activity against TERT-positive tumor cells. Virus Res 220: 172-178, 2016.

83. Rhode PR, Egan JO, Xu W, Hong H, Webb GM, Chen X, Liu B, Zhu X, Wen J, You L, et al: Comparison of the superagonist complex, ALT-803, to IL15 as cancer immunotherapeutics in animal models. Cancer Immunol Res 4: 49-60, 2016.

84. Yan Y, Li S, Jia T, Du X, Xu Y, Zhao Y, Li L, Liang K, Liang W, Sun H and Li R: Combined therapy with CTL cells and oncolytic adenovirus expressing IL-15-induced enhanced antitumor activity. Tumour Biol 36: 4535-4543, 2015.

85. Kubo N, Araki K, Kuwano H and Shirabe K: Cancer-associated fibroblasts in hepatocellular carcinoma. World J Gastroenterol 22: 6841-6850, 2016.

86. Chen $X$ and Song E: Turning foes to friends: Targeting cancer-associated fibroblasts. Nat Rev Drug Discov 18: 99-115, 2019.

87. Feig C, Jones JO, Kraman M, Wells RJ, Deonarine A, Chan DS, Connell CM, Roberts EW, Zhao Q, Caballero OL, et al: Targeting CXCL12 from FAP-expressing carcinoma-associated fibroblasts synergizes with anti-PD-L1 immunotherapy in pancreatic cancer. Proc Natl Acad Sci USA 110: 20212-20217, 2013. 
88. Erdogan B, Ao M, White LM, Means AL, Brewer BM, Yang L, Washington MK, Shi C, Franco OE, Weaver AM, et al: Cancer-associated fibroblasts promote directional cancer cell migration by aligning fibronectin. J Cell Biol 216: 3799-3816, 2017.

89. Erdogan B and Webb DJ: Cancer-associated fibroblasts modulate growth factor signaling and extracellular matrix remodeling to regulate tumor metastasis. Biochem Soc Trans 45: 229-236, 2017.

90. Arwert EN, Milford EL, Rullan A, Derzsi S, Hooper S, Kato T, Mansfield D, Melcher A, Harrington KJ and Sahai E: STING and IRF3 in stromal fibroblasts enable sensing of genomic stress in cancer cells to undermine oncolytic viral therapy. Nat Cell Biol 22: 758-766, 2020.

91. Puig-Saus C, Gros A, Alemany R and Cascallo M: Adenovirus i-leader truncation bioselected against cancer-associated fibroblasts to overcome tumor stromal barriers. Mol Ther 20: 54-62, 2012.

92. Jing Y, Chavez V, Ban Y, Acquavella N, El-Ashry D, Pronin A, Chen X and Merchan JR: Molecular effects of stromal-selective targeting by uPAR-retargeted oncolytic virus in breast cancer. Mol Cancer Res 15: 1410-1420, 2017.

93. Czekierdowska S, Stachowicz N, Chrosciel M and Czekierdowski A Proliferation and maturation of intratumoral blood vessels in women with malignant ovarian tumors assessed with cancer stem cells marker nestin and platelet derived growth factor PDGF-B. Ginekol Pol 88: 120-128, 2017.

94. Wang R, Chadalavada K, Wilshire J, Kowalik U, Hovinga KE Geber A, Fligelman B, Leversha M, Brennan C and Tabar V: Glioblastoma stem-like cells give rise to tumour endothelium. Nature 468: 829-833, 2010.

95. Wang S, Aurora AB, Johnson BA, Qi X, McAnally J, Hill JA, Richardson JA, Bassel-Duby R and Olson EN: The endothelial-specific microRNA miR-126 governs vascular integrity and angiogenesis. Dev Cell 15: 261-271, 2008.

96. Feng SD, Mao Z, Liu C, Nie YS, Sun B, Guo M and Su C: Simultaneous overexpression of miR-126 and miR-34a induces a superior antitumor efficacy in pancreatic adenocarcinoma. Onco Targets Ther 10: 5591-5604, 2017.

97. Harada A, Uchino J, Harada T, Nakagaki N, Hisasue J, Fujita $\mathrm{M}$ and Takayama K: Vascular endothelial growth factor promoter-based conditionally replicative adenoviruses effectively suppress growth of malignant pleural mesothelioma. Cancer Sci 108: 116-123, 2017.
98. Chen QN, Chen X, Chen ZY, Nie FQ, Wei CC, Ma HW, Wan L, Yan S, Ren SN and Wang ZX: Long intergenic non-coding RNA 00152 promotes lung adenocarcinoma proliferation via interacting with EZH2 and repressing IL24 expression. Mol Cancer 16: 17, 2017.

99. Zhuo B, Wang R, Yin Y, Zhang H, Ma T, Liu F, Cao H and Shi Y: Adenovirus arming human IL-24 inhibits neuroblastoma cell proliferation in vitro and xenograft tumor growth in vivo. Tumour Biol 34: 2419-2426, 2013.

100. Zhang Y and Zheng J: Functions of immune checkpoint molecules beyond immune evasion. Adv Exp Med Biol 1248: 201-226, 2020.

101. Li K and Tian H: Development of small-molecule immune checkpoint inhibitors of PD-1/PD-L1 as a new therapeutic strategy for tumour immunotherapy. J Drug Target 27: 244-256, 2019.

102. Kurachi M, Barnitz RA, Yosef N, Odorizzi PM, DiIorio MA, Lemieux ME, Yates K, Godec J, Klatt MG, Regev A, et al: The transcription factor BATF operates as an essential differentiation checkpoint in early effector CD8+ T cells. Nat Immunol 15 : 373-383, 2014

103. Deng J, Wang ES, Jenkins RW, Li S, Dries R, Yates K, Chhabra S, Huang W, Liu H, Aref AR, et al: CDK4/6 inhibition augments antitumor immunity by enhancing T-cell activation. Cancer Discov 8: 216-233, 2018.

104. Johnson DB, Sullivan RJ and Menzies AM: Immune checkpoint inhibitors in challenging populations. Cancer 123: 1904-1911, 2017.

105. Zhang Y, Zhang H, Wei M, Mou T, Shi T, Ma Y, Cai X, Li Y, Dong $\mathrm{J}$ and Wei J: Recombinant adenovirus expressing a soluble fusion protein PD-1/CD137L subverts the suppression of CD8 ${ }^{+}$ T cells in HCC. Mol Ther 27: 1906-1918, 2019.

106. Du T, Shi G, Li YM, Zhang JF, Tian HW, Wei YQ, Deng H and Yu DC: Tumor-specific oncolytic adenoviruses expressing granulocyte macrophage colony-stimulating factor or anti-CTLA4 antibody for the treatment of cancers. Cancer Gene Ther 21: 340-348, 2014.

107. Dias JD, Hemminki O, Diaconu I, Hirvinen M, Bonetti A, Guse K, Escutenaire S, Kanerva A, Pesonen S, Löskog A, et al: Targeted cancer immunotherapy with oncolytic adenovirus coding for a fully human monoclonal antibody specific for CTLA-4. Gene Ther 19: 988-998, 2012. International (CC BY-NC-ND 4.0) License. 